\title{
Evaluation of the Epidermal Growth Factor Receptor (EGFR) and c-erbB-2 in Superspreading-type and Penetrating-type Gastric Carcinoma
}

\author{
KEISHIRO AOYAGI, KIKUO KOHFUJI, SHOJIRO YANO, NAOTAKA MURAKAMI, \\ MOTOSHI MIYAGI, JINRYO TAKEDA AND KAZUO SHIROUZU \\ Department of Surgery, Kurume University School of Medicine, \\ Kurume 830-0011, Japan
}

\begin{abstract}
Summary: The expression of epidermal growth factor (EGF), epidermal growth factor receptor (EGFR), transforming growth factor $\alpha$ (TGF $\alpha$ ), and of c-erbB-2 was immunohistochemically investigated in resected gastric carcinoma (in 39 cases of superspreading type and in 11 cases of penetrating type), to understand the differential biological features of these two types of gastric carcinoma. EGF, EGFR and c-erbB-2 positive cases were preferentially found in penetrating type rather than in superspreading type $(p<0.05, p<0.01$, and $p<0.05$, respectively). The positive rates of EGFR and c-erbB-2 were significantly higher in submucosal gastric carcinoma than in intramucosal gastric carcinoma $(p<0.01, p<0.05$, respectively). These results suggested that the autocrine mechanism of the growth factors and the expression of c-erbB-2 were correlated to the degree of gastric wall invasion.
\end{abstract}

Key words growth factor, c-erbB-2, superspreading type, penetrating type, gastric carcinoma

\section{INTRODUCTION}

There are two progressive types of gastric carcinoma; superspreading type and penetrating type. The aim of this study was to characterize the biological differences between superficial spreading type and small sized infiltrating type. We therefore performed immunohistochemical studies using epidermal growth factor (EGF), transforming growth factor $\alpha$ (TGF $\alpha)$, epidermal growth factor receptor (EGFR) which is a receptor of EGF and TGF $\alpha$, and using c-erbB-2 which is recognized as a cancer gene similar to the EGFR gene [1], in superspreading intramucosal gastric cancer of $5 \mathrm{~cm}$ or larger in size, and in small-sized advanced gastric carcinoma of $2 \mathrm{~cm}$ or smaller in size.

\section{MATERIALS AND METHODS}

\section{Tissues}

Samples of gastric carcinoma were taken from the stomach of 151 patients who had undergone gastrectomy for gastric carcinoma. There were 39 cases of superspreading intramucosal gastric carcinoma that were $5 \mathrm{~cm}$ or larger, and 11 cases of small-sized advanced gastric carcinoma that were $2 \mathrm{~cm}$ or smaller. The remaining 63 cases of intramucosal gastric carcinoma smaller that $5 \mathrm{~cm}$ and the 38 cases of submucosal gastric carcinoma were used as control. All samples were routinely processed in paraffinembedded, $\mathrm{H} \&$ E-stained sections. Clinical and histological classifications were based on the General Rules for Gastric Cancer Study in Japan [2].

\section{Immunohistochemistry}

Each 4- $\mu \mathrm{m}$ paraffin section was stained using the avidin-biotin-peroxidase technique (ABC method). In brief, after paraffin sections were deparaffinized, sections were washed in PBS, and then immersed in methanol containing $0.3 \% \mathrm{H}_{2} \mathrm{O}_{2}$ for 30 min to block the endogenous peroxidase activity. The section was then incubated with anti-EGF polyclonal antibody 
(Oncogene Research Product, Boston, MA, USA), anti-TGF $\alpha$ monoclonal antibody (Oncogene Research Product, Boston, MA, USA), anti-EGFR polyclonal antibody (Oncogene Research Product, Boston, MA, USA) and anti c-erbB-2 polyclonal antibody (Zymed Laboratories, Inc., South San Francisco, CA, USA) for at least $12 \mathrm{hrs}$ at $4{ }^{\circ} \mathrm{C}$, followed by incubation with biotinylated rabbit antimouse or goat anti-rabbit serum for $30 \mathrm{~min}$ and incubation with streptavidin-peroxidase complex for $30 \mathrm{~min}$. Staining was developed by incubating the sections in 3-amino-9-ethylcarbazole (AEC) for 5 min. Each section was counterstained with hematoxylin, and mounted. Nonimmuno serum was used for the negative control for each staining. The intensity of the immunohistochemical reaction was evaluated in at least ten random microscopic high-power fields at $400 \times$ magnification. When more than $10 \%$ cells were positive on immunohistochemical reaction to EGF, TGF $\alpha$ or EGFR they were scored as positive $(+)$, and when more than $5 \%$ cells were positive on immunohistochemical reaction to c-erbB-2, they were scored as positive $(+)$.

\section{Statistical analysis}

The $\chi^{2}$ test was used for comparing group frequencies, as appropriate. $\mathrm{p}<0.05$ by the two-tailed test was considered statistically significant.

\section{RESULTS}

\section{Superspreading gastric carcinoma}

Of the 39 patients with a superspreading intramucosal gastric carcinoma that was $5 \mathrm{~cm}$ or larger, there were 23 males and 16 females, ranging in age from 23 to 78 years (mean age 57.7 years). Twenty-three lesions occurred mainly in the $M$ region, 13 lesions occurred mainly in the $\mathrm{L}$ region, and 3 lesions occurred mainly in the $U$ region. On macroscopic type, the depressive type was most common, accounting for 21 lesions, the elevated type accounted for 7 lesions, the flat type accounted for 3 lesions and mixed type accounted for 8 lesions. Ulcer or ulcer scar was recognized in 13 lesions. On histological type, the differentiated type accounted for 13 lesions (tub1: 9 lesions, tub2: 3 lesions, pap: 1 lesion), and the undifferentiated type accounted for 26 lesions (sig: 21 lesions, por: 5 lesions) (Table 1). The number of mixed pattern type histologically was 6 lesions $(15.4 \%)$. The overall mean tumor diameter was $7.17 \mathrm{~cm}$, ranging from 5.0 to $14.5 \mathrm{~cm}$. Two
TABLE 1.

Correlation between histology and progressive types gastric carcinoma

\begin{tabular}{|c|c|c|c|c|c|c|c|c|}
\hline \multirow{2}{*}{$\begin{array}{c}\text { Progressive } \\
\text { type }\end{array}$} & \multicolumn{4}{|c|}{ Differentiated type } & \multicolumn{4}{|c|}{ Undifferentiated type } \\
\hline & tub1 & tub2 & pap & total & por & sig & muc & total \\
\hline Superspreading & 9 & 3 & 1 & 137 & 5 & 21 & 0 & 267 \\
\hline Small advanced & 0 & 8 & 0 & 8 & 1 & 1 & 1 & 3 \\
\hline
\end{tabular}

patients showed positive lymph node metastasis (5.1\%), and both involved the N1 lymph node. Both lesions were depressed type macroscopically, and undifferentiated type with an ulcer scar histologically. In prognosis, except for 5 patients lost to followup, and 4 patients that died of other disease, 30 patients are still alive without recurrence. Moreover, 14 patients are alive for longer than 5 years since resection.

\section{Small-sized advanced gastric carcinoma}

Of the 11 patients with a small-sized advanced gastric carcinoma that was $2 \mathrm{~cm}$ or smaller than 2 $\mathrm{cm}$, there were 7 males and 4 females, ranging in age from 34 to 86 years (mean age 61.8 years). Six lesions occurred mainly in the $M$ region, 4 lesions occurred mainly in the $\mathrm{L}$ region, and one lesion occurred in the stump site of the remnant stomach. On macroscopic type, type I accounted for 2 lesions, type II accounted for 5 lesions, type III accounted for 2 lesions, and type $\mathrm{V}$ accounted for 2 lesions. On histological type, 8 lesions were differentiated type (tub2), and 3 lesions were undifferentiated type accounted for 3 cases (por2: 1 lesion, sig: 1 lesion, muc: 1 lesion) (Table 1). The number of mixed-pattern type histologically was 4 lesions $(44.4 \%)$, and component of differentiated type histologically was recognized in 3 of these lesions. In stroma pattern, the medullary type accounted for 3 lesions, intermediate type accounted for 5 lesions, and schirrous type accounted for 3 lesions. The overall mean tumor diameter was $1.68 \mathrm{~cm}$, ranging from 0.8 to $2.0 \mathrm{~cm}$. Only one patient showed positive lymph node metastasis $(9.1 \%)$, and involved the N1 lymph node. In prognosis, except for 1 patient lost to follow-up, and 2 patients that died of other disease, 8 patients are still alive without recurrence. Moreover, 6 patients are alive for longer than 5 years. The number of small-sized advanced gastric carcinoma that was differentiated type was significantly more than that of superspreading gastric carcinoma. On the other 
hand, the number of superspreading gastric carcinoma that was undifferentiated type was significantly more than that of small-sized advanced gastric carcinoma (Table 1). The number of small-sized advanced gastric carcinoma that was mixed pattern type histologically was more than that of superspreading gastric carcinoma, but not statistically significant.

The expression of growth factors and c-erbB-2 of early gastric carcinoma

The positive rate of EGF, TGF $\alpha$, EGFR, and of

TABLE 2.

Correlation between tumor size and growth factors or c-erbB-2 in intramucosal gastric carcinoma

\begin{tabular}{rccrc}
\hline Tumor size $(\mathrm{mm})$ & EGF & TGF $\alpha$ & EGFR & c-erbB-2 \\
\hline$-20(\mathrm{n}=40)$ & $7.5 \%$ & $20.5 \%$ \\
$20-50(\mathrm{n}=23)$ & $26.1 \%$ & $56.5 \%$ & $40.0 \%$ & $7.7 \%$ \\
$50-\quad(\mathrm{n}=39)$ & $15.3 \%$ & $33.3 \%$ & $30.8 \%$ & $25.6 \%$ \\
\hline & $14.7 \%$ & $35.3 \%$ & $38.2 \%$ & $22.5 \%$ \\
\hline
\end{tabular}

$*: \mathrm{p}<0.01, * *: \mathrm{p}<0.05$

TABLE 3.

The expression of growth factors and c-erbB-2 in early gastric carcinoma

\begin{tabular}{lcccc}
\hline & EGF & TGF $\alpha$ & EGFR & c-erbB-2 \\
\hline $\begin{array}{l}\text { Intramucosal } \\
\text { carcinoma }(\mathrm{n}=102)\end{array}$ & $14.7 \%$ & $35.3 \%$ & $38.2 \%$ & $22.5 \%$ \\
$\begin{array}{l}\text { Submucosal } \\
\text { carcinoma }(\mathrm{n}=38)\end{array}$ & $15.8 \%$ & $47.4 \%$ & $76.3 \%$ & $42.1 \%$ \\
\hline & $15.0 \%$ & $38.6 \%$ & $48.6 \%$ & $27.9 \%$ \\
\hline
\end{tabular}

$*: \mathrm{p}<0.01, * *: \mathrm{p}<0.05$

TABLE 4.

The expression of growth factors and c-erbB-2 in superspreading and in penetrating type gastric carcinoma

\begin{tabular}{lcccc}
\hline & EGF & TGF $\alpha$ & EGFR & c-erbB-2 \\
\hline $\begin{array}{l}\text { Superspreading } \\
\text { type (n=39) }\end{array}$ & $15.3 \%$ & $33.3 \%$ & $30.8 \%$ & $25.6 \%$ \\
$\begin{array}{l}\text { Small submucosal } \\
\text { carcinoma (n=10) }\end{array}$ & $20.0 \%$ & $* 60.0 \%$ & $70.0 \%$ & $* * 30.0 \%$ \\
$\begin{array}{l}\text { Penetrating type } \\
(\mathrm{n}=11)\end{array}$ & $54.5 \%$ & $63.6 \%$ & $81.8 \%$ & $63.6 \%$ \\
\hline
\end{tabular}

$*: \mathrm{p}<0.05, * *: \mathrm{p}<0.01$
c-erbB-2 was $14.7 \%, 35.3 \%, 38.2 \%$, and $22.5 \%$, respectively, in intramucosal gastric carcinoma. In tumor size, the positive rate of TGF $\alpha$ and c-erbB-2 of size from 2 to $5 \mathrm{~cm}$ was significantly more than that of size smaller than $2 \mathrm{~cm}$ (Table 2). The positive rate of EGF, TGF $\alpha$, EGFR, and of c-erbB-2 was $15.8 \%, 47.4 \%, 76.3 \%$, and $42.1 \%$, respectively, in submucosal gastric carcinoma (Table 3). The positive rate of EGF, TGF $\alpha$, EGFR, and of c-erbB-2 in submucosal gastric carcinoma was more than that in intramucosal gastric carcinoma, and there were significantly more in EGFR and c-erbB-2 (Table 3).

The expression of growth factors and c-erbB-2 of superspreading gastric carcinoma and of small-sized advanced gastric carcinoma

The positive rate of EGF, TGF $\alpha$, EGFR, and of c-erbB-2 was $15.3 \%, 33.3 \%, 30.8 \%$, and $25.6 \%$, respectively, in superspreading gastric carcinoma (Table 4). The positive rate of EGF, TGF $\alpha$, EGFR, and of c-erbB-2 was $54.5 \%, 63.6 \%, 81.8 \%$, and $63.6 \%$, respectively, in small-sized advanced gastric carcinoma (Table 4). The positive rate of EGF, TGF $\alpha$, EGFR, and of c-erbB-2 was $20.0 \%, 60.0 \%$, $70.0 \%$, and $30.0 \%$, respectively, in submucosal carcinoma smaller than $2 \mathrm{~cm}$ (Table 4). The positive rate of EGF, TGF $\alpha$, EGFR, and of c-erbB-2 in smallsized advanced gastric carcinoma was more than that in superspreading gastric carcinoma (Table 4). In particular, there were significant differences in EGF, EGFR, and in c-erbB-2 (Table 4). The positive rate of EGF, TGF $\alpha$, EGFR, and of c-erbB-2 in submucosal carcinoma smaller than $2 \mathrm{~cm}$ was more than that in superspreading gastric carcinoma, but with no significant difference (Table 4). The positive rate of EGF, TGF $\alpha$, EGFR, and of c-erbB-2 in small-sized advanced gastric carcinoma was more than that in submucosal carcinoma smaller than $2 \mathrm{~cm}$, but with no significant difference (Table 4).

\section{DISCUSSION}

The depressed type macroscopically and signet ring cell carcinoma histologically were the most common in superspreading gastric carcinoma. On the other hand, the numbers of differentiated type and of mixed-pattern type histologically in small-sized advanced gastric carcinoma were more than those in superspreading gastric carcinoma. Two cases with lymph node metastasis in superspreading gastric carcinoma involved N1 lymph node and both had an ulcer scar. Several authors reported that intramucosal 
gastric carcinoma larger than $5 \mathrm{~cm}$ or which had ulcer or ulcer scar had an increased risk to lymph node metastasis [3-5]. In small-sized gastric carcinoma, only one case with lymph node metastasis involved the N1 lymph node, and there was no liver or peritoneal metastasis. The prognoses for both superspreading and small-sized gastric carcinoma were good, and there was no postoperative recurrence. There was no relationship among growth factors, c-erbB-2 and tumor size in intramucosal gastric carcinoma. However, the positive rate of EGFR in submucosal gastric carcinoma smaller than $2 \mathrm{~cm}$ was more than that in superspreading gastric carcinoma, and the positive rate of EGF, EGFR and c-erbB-2 in small-sized gastric carcinoma was significantly more than that in superspreading gastric carcinoma. These results suggested that the EGF-EGFR system and cerbB-2 were more influential on the vertical invasion than on the horizontal invasion. Hirayama et al. [6] reported that in gastric carcinoma, the PEN-type early gastric carcinoma had high proliferative activity, and EGF influenced invasion and proliferation of PEN-type early gastric carcinoma. Kohfuji et al. [7] reported that EGF, EGFR, and TGF $\alpha$ positive cases were preferentially found in penetrating type rather than in superspreading type, suggesting that growth and invasion of carcinoma cells, especially in penetrating type, may depend on the autocrine mechanism of growth factors, and that the malignant potential of signet ring cells in superspreading type was lower than that in penetrating type. Tokunaga et al. [8] reported that gastric carcinoma exhibiting EGF and EGFR simultaneously showed a greater degree of local invasion and lymph node metastasis. Our results suggested that the autocrine mechanism of the growth factors was correlated with the degree of gastric wall invasion, too. Yonemura et al. [9] reported that the positive staining of c-erbB-2 was correlated with positive serosal invasion, lymph node metastasis, larger tumors (greater than $6 \mathrm{~cm}$ ), and with prognosis. Tokunaga et al. [8] reported that the expression of c-erbB-2 was correlated with the histological type, lymph node metastasis, serosal invasion of the tumor, and with prognosis. In our study, the positive rate of c-erbB-2 in tumors from 2 to $5 \mathrm{~cm}$ in size was significantly more than that in those smaller than $2 \mathrm{~cm}$, in intramucosal gastric carcinoma, and that the expression of c-erbB-2 was correlated with the degree of gastric wall invasion.

\section{REFERENCES}

1. Yamamoto T, Ikawa S, Akiyama T, Semba K, Nomura N et al. Similarity of protein encoded by the human c-erbB2 gene to epidermal growth factor receptor. Nature 1986; 319:230-234.

2. Japanese Gastric Cancer Association. The General Rules for Gastric Cancer Study 13th edn, Kanehara, Tokyo, 1999. (in Japanese)

3. Hayashi T, Nashimoto A, Tanaka O, and Sasaki J. A clinicopathological study of lymph node positive intramucosal gastric cancer. Jpn J Gastroenterol Surg 1995; 28:766-771. (in Japanese)

4. Kitaoka H, Yoshikawa K, Suzuki M, Yoshida S, Yamaguchi $\mathrm{H}$ et al. Study on local resection of the tumor with preservation of the regional lymph nodes for early gastric cancer. J Jpn Cancer Ther 1983; 18:969-978. (in Japanese)

5. Iwashita A, Yamada Y, Arita M, Yao T, Takasaki J et al. Indication of endoscopic curative resection for early gastric carcinoma from a pathologic point of view. I to Cho (Stomach and Intestine) 1991; 26:265-274. (in Japanese)

6. Hirayama D, Fujimori T, Arao M, and Maeda S. Clinicopathological and immunohistochemical study on penetrating and superficial spreading type of early gastric cancers. Jpn J Gastroenterol 1990; 87:2434-2443. (in Japanese)

7. Kohfuji K, Hashimoto K, Kodama I, Aoyagi K, Ota J et al. Expression of the growth factors (EGF, EGFR, and TGF $\alpha$ ) and PCNA in superspreading and penetrating types of gastric carcinomas. J Jpn Surg Soc 1993; 94:988-992. (in Japanese)

8. Tokunaga A, Onda M, Okuda T, Teramoto T, Fujita I et al. Clinical significance of epidermal growth factor (EGF), EGF receptor, and c-erbB-2 in human gastric cancer. Cancer 1995; 75:1418-1425.

9. Yonemura Y, Ohoyama S, Ninomiya I, Kinoshita K, Fushida $\mathrm{S}$ et al. Correlationship between c-erbB-2 protein expression and clinical outcome in gastric cancer. Jpn J Gastroenterol Surg 1990; 23:2747-2750. (in Japanese) 